Document downloaded from:

http://hdl.handle.net/10251/51843

This paper must be cited as:

Andrés Navarro, B.; Macedo, P.; Camarinha Matos, LM.; Poler Escoto, R. (2014). Achieving coherence between Strategies and Value Systems in collaborative networks. IFIP Advances in information and communication technology. 434:261-272. doi:10.1007/978-3-662-44745-1_26.

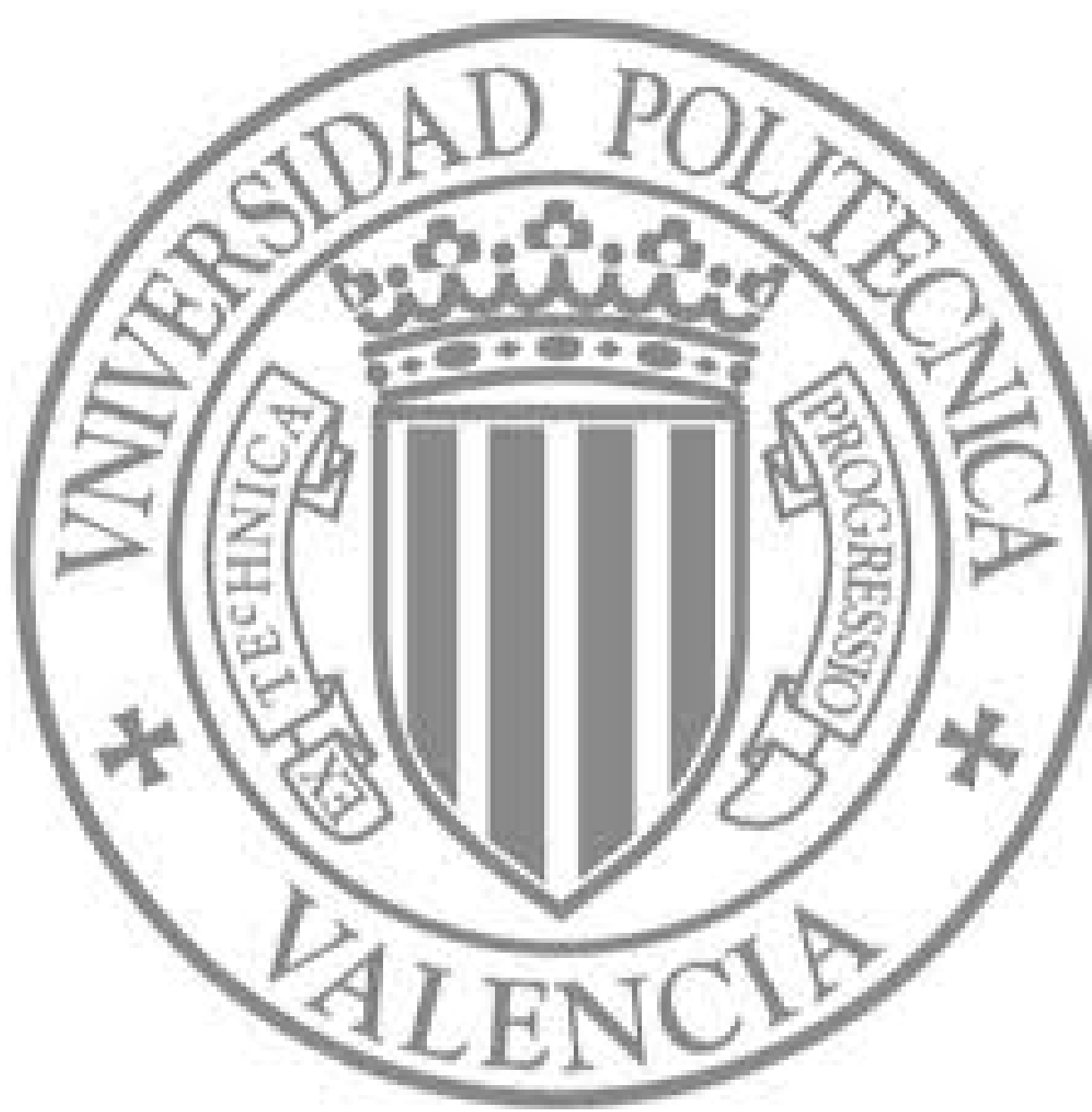

The final publication is available at

http://link.springer.com/chapter/10.1007/978-3-662-44745-1_26

Copyright 


\title{
Achieving Coherence between Strategies and Value Systems in Collaborative Networks
}

\author{
Beatriz Andres ${ }^{1}$, Patricia Macedo ${ }^{2,4}$, Luis M. Camarinha-Matos ${ }^{3,4}$ and Raul Poler ${ }^{1}$ \\ ${ }^{1}$ Research Centre on Production Management and Engineering (CIGIP), Universitat \\ Politècnica de València (UPV), Plaza Ferrándiz y Carbonell 2, 03801 Alcoy, Spain \\ ${ }^{2}$ School of Technology of Setúbal, Polytechnic Institute of Setúbal, Portugal \\ ${ }^{3}$ Faculty of Sciences and Technology, New University of Lisbon, Portugal \\ ${ }^{4}$ Uninova Institute, Centre of Technology and Systems, Portugal \\ beaanna@cigip.upv.es, patricia.macedo@estsetubal.ips.pt, cam@uninova.pt, rpoler@cigip.upv.es
}

\begin{abstract}
Collaborative networks that emerge as consortia to deal with new market opportunities consist of different autonomous entities. Each one holds a set values and defines its own strategies in order to deal with its defined objectives. The enterprises heterogeneity leads sometimes to contradictory objectives, and misalignment of value systems and strategies. Enterprises willing to participate in a collaborative network, as thus willing to avoid these misalignments, have to achieve coherence between the strategies they activate and the values they hold. To facilitate achieving such coherence, this paper contributes with an approach to identify the strategies that should be activated in order to be coherent with the values held by each enterprise. It specifically considers the scenario in which consortia are temporarily formed and values and strategies are set out in the short term. A potential application is exemplified through a numerical example.
\end{abstract}

Keywords: value systems alignment, strategies alignment, collaborative networks, consortium, emergent core value.

\section{Introduction}

Collaborative networks have been widely studied over the last years due to their decisive contribution to small and medium enterprises (SMEs) performance in a context of market turbulence. According to [1], collaborative networks are composed of autonomous and heterogeneous entities which collaborate in order to better achieve common or compatible goals that would be never achieved by isolate entities. In spite of the benefits derived from collaboration [2], SMEs can face a number of challenges when participating in collaborative networks, such as sharing goals, aligning strategies, achieving suitable levels of trust, reaching agreements in practices, and aligning values [3] [4] [5].

This paper particularly focuses on the value systems alignment and the strategies alignment issues. The main aim is to provide an approach to deal with the coherence between the strategies activated or operationalised by collaborative partners and the 
value systems held by the enterprises belonging to the network. The value system is more permanent in time while the strategies have a specific duration throughout the collaborative consortium. In other words, a strategy is activated at a defined time period and finishes after having been performed, when the objective has been achieved.

In order to address the paper's purpose, the concepts and models to deal with the strategies alignment and the value systems alignment are presented (section 2). After that, the research motivation is formulated in section 3. The research approach, in section 4 develops the solution proposal to cope with the raised research motivation. In order to provide an intuitive insight on the developed approach, a numerical example is presented in section 5. Finally, conclusions and future research lines are presented in section 6 .

\section{Background}

This section provides a brief overview of the concepts of strategies alignment and value systems alignment. The adopted modelling approaches are given in both cases.

The alignment concept is considered as the compatibility of the value system or the strategies defined by one enterprise with regards to the value systems or strategies belonging to other networked enterprises. Misalignments appear when incompatibilities and negative influences arise among network partners.

\subsection{Strategies Alignment}

The business objectives are statements that establish what is to be achieved within the enterprise, but without specifying how to achieve them. Hence, enterprises define strategies as a set of actions to be performed in order to achieve the defined objectives. The strategies of members in a collaborative network are considered to be aligned when each activated strategy not only promotes the achievement of the objectives defined by the enterprise that raises such strategy but also boosts the accomplishment of the objectives defined by the rest of the networked partners [5].

In order to model the process of strategies alignment, a set of five objects have been defined: (i) the network $\left(n_{n} \in N\right)$, (ii) the set of enterprises forming the network $\left(e_{i} \in E, e_{n i}=\left(e_{i,}, n_{n}\right) \mid e_{i} \in E \wedge n_{n} \in N\right)$, (iii) the objectives defined by each enterprise $\left(\mathrm{o}_{\mathrm{ix}}=\left(\mathrm{o}_{\mathrm{x}}, \mathrm{e}_{\mathrm{i}}\right) \mid \mathrm{o}_{\mathrm{x}} \in \mathrm{O} \wedge \mathrm{e}_{\mathrm{i}} \in \mathrm{E}\right)$, (iv) the key performance indicators (KPIs) to measure

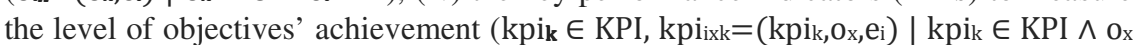
$\in O \wedge e_{i} \in E$ ), and (v) the strategies adopted by each enterprise in order to reach the objectives $\left(\mathrm{s}_{\mathrm{s}} \in \mathrm{S}, \mathrm{S}_{\mathrm{is}}=\left(\mathrm{S}_{\mathrm{s}}, \mathrm{e}_{\mathrm{i}}\right) \mid \mathrm{s}_{\mathrm{s}} \in \mathrm{S} \wedge \mathrm{e}_{\mathrm{i}} \in \mathrm{E}\right)$. A strategy can be active $\left(\mathrm{S}_{i s^{1}}{ }^{1}\right)$, when it is carried out or non-active $\left(\mathrm{Sis}^{0}\right)$ when it is not put into practice.

Collaborative networks success is influenced, inter alia, by the alignment of strategies. Modelling the network allows to identify the set of strategies that if activated achieve the maximum optimum of the enterprises' KPIs and the global network KPI (considering the global KPI as the sum of all the enterprises' KPIs). Accordingly, when there is alignment, the set of activated strategies are characterised 
by promoting positive influences onto all the objectives defined by the networked enterprises, enhancing the establishment of collaboration.

\subsection{Value Systems Alignment}

A Value System defines the set of values and priorities that guide the behaviour of an organisation; as such, it determines or at least constrains the decision-making processes of that organisation. Therefore, the identification and characterisation of the Value Systems of a network and its members is fundamental when attempting to improve collaboration. The Value Systems are aligned when the core values of one member are compatible with the core values of another, and therefore, the potential for emergence of conflicts is lower.

The set of characteristics that each enterprise $\left(e_{i} \in E\right)$ (or network $\left(n_{n} \in N\right)$ ) considers as the most important for itself and that motivate or regulate its behaviour are called core-values $\left(\mathrm{cv}_{\mathrm{i}} \in \mathrm{CV}\right)$. According to the conceptual model proposed in [6] the set of core-values, of an entity $\left(e n t_{i} \in(E \cup N)\right)$ and respective preferences (priority $\mathrm{w}_{\mathbf{i}} \in\left(\right.$ fair,high,very high)) are represented by the core-evaluation perspective (cep $\mathrm{x}_{\mathrm{x}}$ $=\left(d v_{x}, w_{x}\right) \mid d v_{x}=<v_{1}, c_{2}, . . c v_{n}>\wedge w_{v}=\left\langle w_{1}, w_{2}, . . w_{n}>\right)$, which is part of the core value system.

Aiming to provide methods to systematically analyse core value systems in collaborative environments, an analysis framework based on qualitative causal maps and graphs, was proposed in [7]. This framework defines two types of elementary maps:

(i) Core-values influence map (CVIM), which is a cognitive fuzzy map where each directional edge $\left(\mathrm{icV}_{\mathrm{ij}}=\left(\mathrm{CV}_{\mathrm{i}}, \mathrm{CV}, \mathrm{p}, \mathrm{s}\right)\right)$ represents the influence between core-values. The positive or negative influence is specified by the signal (s) of the edge and its intensity (p) is defined by a qualitative label (low, moderate, high);

(ii) Organisation's core-values maps and CN's core-values maps (CVM) are unidirectional graphs, where each edge $\left(e \mathrm{i}_{\mathrm{j}}=\left(\mathrm{ent}_{\mathrm{i}}, \mathrm{Cv}_{\mathrm{j}}, \mathrm{W}_{\mathrm{ij}}\right)\right)$ has a qualitative label that represents the core-value priority $\left(\mathrm{w}_{\mathrm{i}}\right)$ to a specific organisational entity (enti).

Starting with these elementary maps, it is possible to aggregate them in order to build maps that evidence the impact of one core value system into another, facilitating the value systems alignment, and thus allowing an easy identification of the synergies and potential conflicts among network members [7].

\section{Research Motivation}

When a new specific business opportunity appears, a new temporary collaborative consortium, i.e. a virtual organisation (VO), is formed [1]. A set of heterogeneous enterprises take part in the consortium, each of them with different expectations and different value systems, which are sometimes incompatible. Accordingly, the strategies activated by one enterprise could be contradictory to achieve the objectives of other enterprises. The perception of outcomes is also likely to be different for each 
of the collaborative partners belonging to a new consortium. These different perceptions are related to the values of each enterprise [8]. Besides this, each consortium has a specific duration, ending once the business opportunity has been fulfilled. In this context, for each specific enterprise, the core values held could change when a new collaborative consortium is created. In the light of this, two scenarios can be considered:

(i) New values may appear, induced by the newly created consortium. Once the consortium is created, new values can be adopted by the entities forming it, to specifically carry out a collaborative opportunity. To exemplify this case, let us consider two $\mathrm{SMEs}\left(\mathrm{SME}_{1}, \mathrm{SME}_{2}\right)$. The core values held by $\mathrm{SME}_{1}$ are knowledge and reputation, while the core values held by $\mathrm{SME}_{2}$ are standardisation and social awareness. Both SMEs take part in a new collaborative consortium, i.e. a consortium created to participate in a joint research project. In this concrete example a new core value might emerge in both enterprises, that is innovation. Probably, the new values, such as the innovation in this example, will remain even after the dismantling of the consortium, namely if the outcomes of that initiative were considered positive to both SMEs.

(ii) The priority of core values change, increasing or decreasing their importance according to the context of the collaborative consortium. Unlike the previous case, this scenario considers that not always new values emerge when a consortium is created. However, the priority of some core values held by the enterprises can be temporarily modified within the context of the consortium. Considering the example stated before, let us assume that the priorities are initially defined as follows: $\mathrm{SME}_{1}$ knowledge (fair) and reputation (very high) and $\mathrm{SME}_{2}$ standardisation (high) and social awareness (high). However, once a consortium is created, the priorities of these core values might change according to the consortium's nature. In our example, the consortium is created to participate in a joint research project and therefore the priorities might temporarily change for this context as follows: $\mathrm{SME}_{1}$ knowledge (very high) and reputation (very high), and $\mathrm{SME}_{2}$ standardisation (fair) and social awareness (high). The priorities change during the consortium life cycle, and when it finishes, the priorities likely return to the qualitative values initially defined.

Just like the core values temporarily change, appearing new ones or changing their priorities, the objectives also change in each new consortium and consequently, the strategies raised to achieve these objectives.

During the consortium formation, the VO planner evaluates the candidate organisational entities in terms of their value systems in order to select the partners presenting the lowest risk of conflicts, and the highest level of synergies. However, partners' selection based only on the value systems alignment criteria does not assure the sustainability of the collaboration, since there is no guarantee that strategies activated by each member are coherent with the values defined by the rest of members forming the network.

In order to achieve coherence between the activated strategies and the value systems of each collaborative enterprise, the motivation for this work is to identify proper strategies to be activated in order to achieve positive influences between these strategies and the values defined in each consortium.

Figure 1 schematically represents the approach followed in order to deal with the raised research motivation. The attainment of coherence between the activated 
strategies and the value systems of the enterprises forming the collaborative consortium is pursued through the Objectives definition. In other words, the objectives establish the link between strategies and value systems. Firstly, the objectives are defined based on the values held in the enterprise. For instance, taking into account the aforementioned example, the emerged value (innovation) in both enterprises $\left(S M E_{1}\right.$ and $\left.\mathrm{SME}_{2}\right)$ leads to define the following objective: Increase the innovation by $15 \%$. Secondly, the objectives are achieved through the strategies definition, e.g. Participate in a PF7 research project. Thus, this approach allows linking both concepts: strategies and value systems. Since the strategies are directly related with the objectives and those are based on the core values, the alignment of strategies will allow to get coherence between strategies defined and the value systems held. That is a situation in which the strategies fit the core values held by the enterprises belonging to the collaborative consortium.

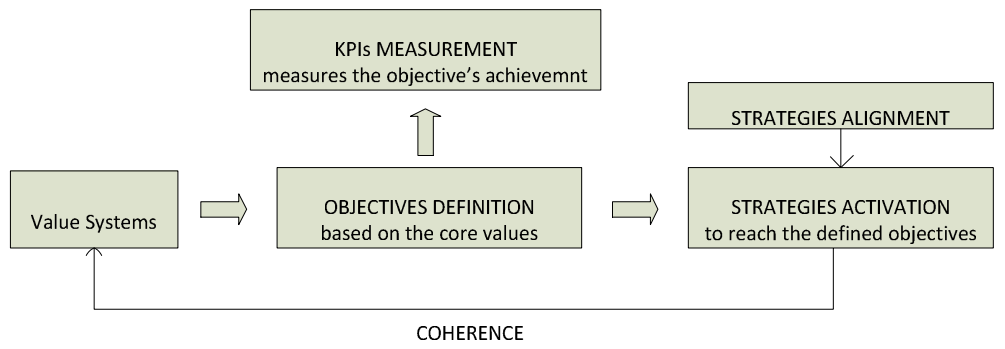

Fig 1. Coherence between the Value Systems and the activated Strategies

\section{Research Approach}

\subsection{Adopted Research Methodology}

The lack of coherence between the adopted strategies and core values may lead to partnership failure [9] [10]. Mechanisms to promote coherence between the activated strategies and the value system of each enterprise of the collaborative consortium are needed. In order to deal with this relevant problem, this paper is based on a theoretical body of knowledge regarding Collaborative Networks, Industrial Management, and System Dynamics. Collaborative Networks discipline contributes with the theoretical base concepts about virtual organisations, consortium formation [11], value system analysis in collaborative contexts [7] and strategies alignment in collaborative networks [5], while Industrial Management contributes with the main concepts about Performance Indicators Management. The Systems Dynamic body of knowledge contributes with optimisation methods applied to identify the set of strategies that are coherent with the Value Systems. Furthermore, the approach is grounded in the Constructive Research method (Figure 2) [12] based on building models and methods to provide a solution domain in the defined problem, in order to create knowledge on how the problem can be solved. Finally, the practical relevance will be shown through an application example. 


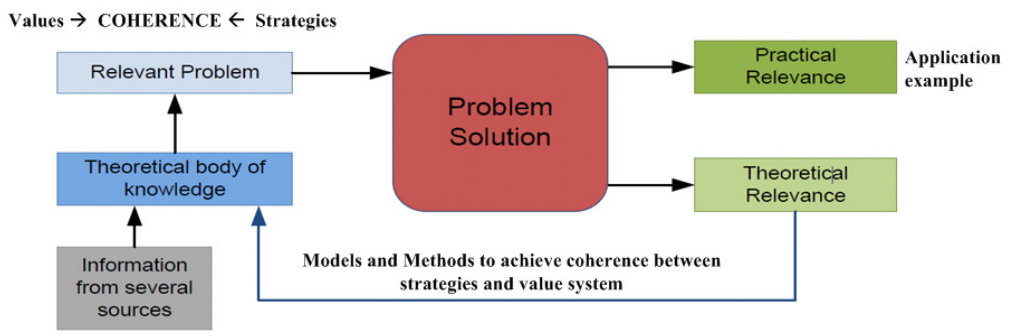

Fig. 2. Constructive Research method

In the current phase of this research, the main aim is to provide models and methods to achieve coherence between the activated strategies and the value systems held by the enterprises of the collaborative network, in order to promote sustainable collaboration. This purpose is carried out through the approach provided in Figure 1, in which the objectives are defined in relation to the core values. This definition of objectives allows linking the core values with the strategies. Having connected both concepts, identifying the aligned strategies that are associated with these objectives will achieve the main purpose of guaranteeing coherence between strategies and value systems.

\subsection{Solution Proposal}

When a new consortium appears, participating enterprises deal with two possible situations, as stated before: (i) the "appearance" of new values, or (ii) the change of priorities of the core values. Considering these two situations, whenever a new collaborative consortium is created, an Emergent Value System appears within the enterprises that are prone to take part. The concept of "emergent" in this work means that new values are adopted or values priority change when the new collaborative consortium is formed.

The conceptual model of the Emergent Value System is represented through a UML class diagram, in which the relations between elements are depicted (Figure 3 ). For better understanding of the relations among the modelled elements in the UML diagram a brief explanation follows.

The Emergent Value System is characterised by the Emergent Evaluation Perspective that gives to each value of the emergent system different priorities (Value Priority). The Emergent Evaluation Perspective has a set of Emergent Core Values. The approach provided by [6] identifies the Core Value and the Core Evaluation Perspective in order to build the enterprises' Value System. Based on this work, the approach here provided adds the New Value concept, corresponding to the new values appearing when a new collaborative consortium is created in order to respond to a new market opportunity. Therefore the Emergent Core Values consist of the New Values and Core Values with changed priorities.

This new approach introduces the definition of Objectives based on the Emergent Core Values. The formulation of Strategies and KPIs are considered in order to deal with the defined Objectives [5]. Furthermore, a new contribution is provided in this work, the Objective Priority in which the objectives are defined with a certain priority 
as well as the core values (Value Priority). As such, a new Set of Prioritised Objectives is defined. Nevertheless, it must be taken into account that the Value Priority is not to be necessarily the same as the Objective Priority, although in some occasions they may coincide. Once the Objectives are defined based on the Emergent Core Values, the Strategies are formulated and the KPIs are designed in order to measure how the Strategies influence the accomplishment of each defined Objective. As the Emergent Core Values are linked with the Objectives, and these in turn are linked with the Strategies, it can be considered that the Emergent Core Values and the Strategies are also linked. Therefore, the identification of the aligned strategies will allow achieving the desired coherence between the Strategies activated and the Emergent Core Values. The set of strategies that are suitable to be activated will positively influence the Emergent Core Values within the networked partners belonging to the new consortium.

The set of aligned strategies are identified through the model provided by [5], in which the strategies are considered aligned if and only if there is a positive increase on the KPIs defined in each networked enterprise. Thus, the optimum performance at both enterprises and network level is obtained.

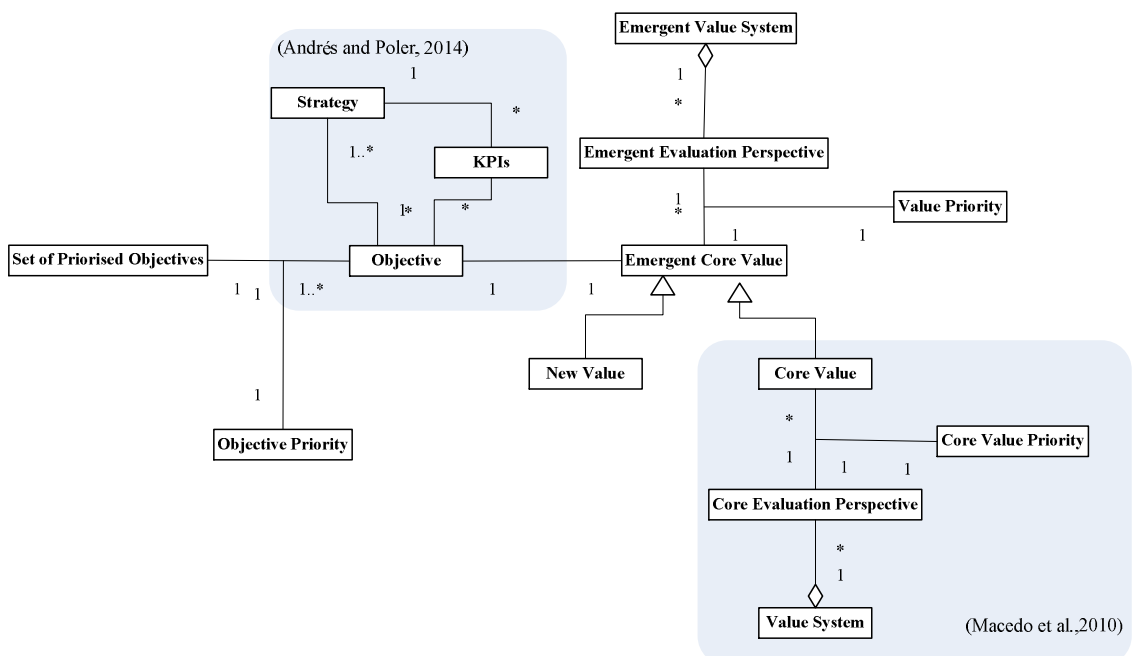

Fig 3. UML class diagram of the conceptual model of Emergent Value System.

\section{Application Example}

The main purpose of this example is to show how to identify the strategies that are aligned in order to be activated. These strategies will be characterised as being coherent with the values defined by the enterprises.

In order to model the strategies alignment process, AnyLogic simulation software is used [13]. This simulation software is founded on the dynamic systems methodology 
providing an optimisation tool that allows to identify the strategies that have positive influences in the objectives defined, both in the same enterprise an in the other networked enterprises. The optimiser maximises the network performance through identifying which strategies activate $\left(s_{i s}{ }^{l}\right)$ in each enterprise in order to achieve the scenario in which the activated strategies are aligned.

The output of the proposed model is the strategy units $\left(s_{i s}\right)$ to be activated in order to achieve the maximum increase on the performance (KPIs) [5]. Strategy units $\left(s_{i s}\right)$ are considered as the number of units of strategy to be activated in $\mathrm{e}_{\mathrm{i}}$ (Table 1).

Table 1. Definition of strategy units (Andrés and Poler, 2014).

\begin{tabular}{l|l}
\hline Variable & Definition \\
\hline$s_{i s}$ & Number of units of strategy $s_{i s}$ to be activated in enterprise $e_{i}$ \\
\hline expenseRatio_s $s_{i s}$ & Cost of one unit of strategy $s_{i s}$ activated in enterprise $e_{i}$ \\
\hline$s_{i s \_} \boldsymbol{m u}$ & $\begin{array}{l}\text { Total monetary units invested in strategy } s_{i s} \text { activated in enterprise } e_{i} \\
s_{i s \_} m u=s_{i s} \text { x expenseRatio__ } s_{i s}\end{array}$ \\
\hline
\end{tabular}

Thus, the optimisation tool in Anylogic software identifies the number of strategy units that should be activated in order to obtain the set of aligned strategies within the network partners. Furthermore, the activated aligned strategies will be characterised by being coherent with the value systems of the enterprises forming the collaborative consortium.

According to the aforementioned, a numerical example is developed hereafter. The example considers modelling two enterprises $\left(e_{1}, e_{2}\right)$ that take part in a new collaborative consortium. Each enterprise initially holds one core value $\left(e_{1}=c v_{1}\right.$ and $\left.e_{2}=c v_{2}\right)$ with its specific degree of priority $\left(e_{1}=w_{1}\right.$ and $\left.e_{2}=w_{2}\right)$. When these enterprises take part in the new consortium, new values appear and the priorities of the initial core values change (Table 2).

Table 2. Core Values

\begin{tabular}{ll|l}
\hline Enterprises $\left(\mathbf{e}_{\mathbf{i}}\right)$ & $\begin{array}{l}\text { Initially defined } \\
\text { Core values set }\left(\mathbf{c v}_{\mathbf{i}}\right) \text { with value priorities }\left(\boldsymbol{w}_{\boldsymbol{i}}\right)\end{array}$ & $\begin{array}{l}\text { New Consortium } \\
\text { Core values set }\left(\mathbf{c v}_{\mathbf{i}}\right) \text { with value priorities }\left(\boldsymbol{w}_{\boldsymbol{i}}\right)\end{array}$ \\
\hline $\mathbf{e}_{\mathbf{1}}$ & Standardisation $($ high $)$ & $\begin{array}{l}\text { Standardisation }(\text { fair }) \text {, Knowledge (very high) } \\
\text { Innovation }(\text { high }), \text { Uniqueness (fair) }\end{array}$ \\
$\mathbf{e}_{2}$ & Uniqueness (very high) & \\
\hline
\end{tabular}

In the developed example the two aforementioned scenarios are considered:

(i) New values may appear. In the new collaboration consortium the new core value of $\mathbf{e}_{1}$ is knowledge with a very high priority, and in $\mathbf{e}_{2}$ the innovation core value appears with a high priority.

(ii) The priority of core values change. In the new collaboration consortium the core values initially defined temporarily change the priority. In $\mathrm{e}_{1}$ the standardisation core value has a high initial priority, but when the consortium is build the initial priority changes to fair. In $\mathrm{e}_{2}$ the uniqueness core value has a very high initial priority and once the new consortium appears the priority momentarily changes to fair. The changes of priority are due to the context of the consortium temporarily changes.

The impact analysis (once the new consortium arises), in terms of core values, of the $\mathrm{e}_{1}$ and the $\mathrm{e}_{2}$, shows that:

- Innovation (e $\left.\mathrm{e}_{2}\right)$ positively influences Knowledge $\left(\mathrm{e}_{1}\right)$ 
- Innovation ( $\left.\mathrm{e}_{2}\right)$ negatively influences Standardisation $\left(\mathrm{e}_{1}\right)$

- Uniqueness $\left(\mathrm{e}_{2}\right)$ negatively influences Standardisation $\left(\mathrm{e}_{1}\right)$

The variables of the new consortium are, then, mathematically characterised and exemplified in Table 3:

- Core Values: core values held by each enterprise $\left(e_{1}=c v_{1}, c v_{2}\right.$ and $e_{2}=c v_{3}$, $\left.c v_{4}\right)$ with its priorities $\left(e_{1}=w_{1}, w_{2}\right.$ and $\left.e_{2}=w_{3}, w_{4}\right)$

- Objectives: for each core value $\left(c v_{i}\right)$ an objective is defined $\left(e_{1}=o_{11}, o_{12}\right.$ and $e_{2}=o_{21}, o_{22}$ ). The objectives definition is based on the core values.

- Strategies: the strategies are set out to achieve the defined objectives $\left(e_{1}=\right.$ $s_{11}, s_{12}$ and $\left.e_{2}=s_{21}, s_{22}\right)$

- KPIs: the objectives are measured through the KPIs $\left(e_{1}=k p i_{111}, k p i_{121}\right.$ and $e_{2}$ $=$ kpi $_{211}$, kpi $\left._{221}\right)$.

- KPIs increase: $\left(\nabla k p i_{i x k}\right)$ shows how one objective $\left(o_{i x}\right)$ is influenced by the activation of a particular strategy $\left(s_{i s}\right)\left(\mathrm{Vkpi}_{i x k}{ }^{i s}\right)$

- KPIs priority: the priority of the KPI is directly related to the priority to achieve the objectives in each enterprise (priority_kpi $i_{i x k}$ )

- Expense Ratio: each strategy $\left(s_{i s}\right)$ has an associated cost that is defined through the expenseRatio_sis (measured in monetary units - m.u.).

- Budget: each enterprise has its own budget to activate the strategies $\left(e_{1}=b_{1}\right.$, $\left.e_{2}=b_{2}\right)$.

The set of core values, objectives, strategies and KPIs are defined in Table 3. The data regarding the KPIs increase, KPIs priority, expense ratio and budget is exemplified in Table 4. Table 4 summarises the data to be introduced in Anylogic simulation software in order to build and solve the numerical example. The optimisation experiment is compiled and the results are depicted in Figure 4. The optimisation tool maximises the KPIs increase ( $\left.\nabla k p i_{i x k}\right)$ through modifying the parameters represented by the strategies $s_{i s}$ (in this example: $e_{1}: s_{11}, s_{12}$ and $e_{2}: s_{21}, s_{22}$ ). On the right side of Figure 4 it is depicted the graph that shows the iterations compiled in the model in order to find the parameters that maximise the solution. Each dot in the graph corresponds to a single simulation run.

The results derived from the example using the optimisation tool (Figure 4), show the strategy units the enterprises have to activate. Thus:

- $e_{1}$ activates 16 units of strategy $s_{12}$, considering that the expense ratio of one unit of $s_{12}$ is 5 m.u., the monetary units invested $s_{12} \_m u$ are 80 m.u. $\left(s_{12} \_m u=\right.$ $16 * 5)$ out of the budged of $e_{1}$ to $\left(b_{1}=100\right)$, and

- $e_{2}$ activates 15 units of strategy $s_{21}$, considering that the expense ratio of one unit of $s_{21}$ is $10 \mathrm{~m} . u$., the monetary units invested $s_{21} \_m u$ are 150 m.u. (s21_mu $=15 * 10), e_{2}$ spends the total budged $\left(b_{1}=150\right)$.

- Furthermore, it is seen that in order to achieve the maximum performance, strategies $\mathbf{S}_{11}\left(\mathbf{e}_{1}\right)$ and $\mathbf{s}_{2}\left(\mathbf{e}_{2}\right)$ will not be activated by the networked enterprises.

This solution shows how the strategies $\mathbf{s}_{\mathbf{1 2}}$ and $\mathbf{s}_{\mathbf{2 1}}$, besides being aligned, are also coherent with the emergent value system in which the knowledge $\left(\mathbf{e}_{1}\right)$ and innovation $\left(\mathbf{e}_{2}\right)$ are the new values, defined with very high and high priorities, respectively. 
Table 3. Objectives, Strategies and KPIs defined in order to achieve the values defined in each networked enterprise

\begin{tabular}{|c|c|c|c|}
\hline Enterprise & Objectives & Strategies & Key Performance Indicators \\
\hline \multirow[t]{2}{*}{$\mathbf{e}_{1}$} & $\begin{array}{l}\text { 0.11: Increase } \\
\text { Standardisation by } \\
5 \%\end{array}$ & $\begin{array}{l}\text { S11: Application, arrangement and enhancement of } \\
\text { standards established in all the enterprise production } \\
\text { processes. Implement Processes Standardisation through } \\
\text { processes definition, identification, documentation, } \\
\text { formalisation and audit. }\end{array}$ & $\mathbf{k p i}_{111}:$ Standardisation_level $=\frac{\text { Standardisation } \quad t}{\text { Standardisation }(t-1)}$ \\
\hline & $\begin{array}{l}\text { o12: Increase by } 25 \% \\
\text { the exchange of } \\
\text { Knowledge among } \\
\text { the partners }\end{array}$ & 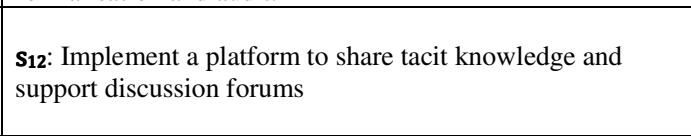 & $\mathbf{k p i}_{121}:$ Knowledge_Increase $=\frac{\text { Knowledge exchange }_{t}}{\text { Knowledge exchange }(t-1)}$ \\
\hline \multirow[b]{2}{*}{$\mathbf{e}_{2}$} & $\begin{array}{l}\text { O.21: Increase } \\
\text { Innovation by } 15 \%\end{array}$ & $\mathbf{s}_{\mathbf{2 1}}:$ Participate in research European Projects in $\mathrm{H} 2 \mathrm{O} 2 \mathrm{O}$ & $\mathbf{k p i}_{211}:$ Degree_Innovation $=\frac{\text { Innovation } t}{\text { Innovation }(t-1)}$ \\
\hline & $\begin{array}{l}\text { O22: Increase the } \\
\text { Uniqueness by } 20 \%\end{array}$ & $\begin{array}{l}\text { S22: Implement the Engineering to Order Strategy (ETO) for } \\
\text { products that require engineering and every customer order } \\
\text { results in a unique set of material elements, procedures and } \\
\text { processes. Unique product that offers original design and } \\
\text { therefore its manufacturing process also has unique features } \\
\text { and options including customisation }\end{array}$ & $\mathbf{k p i}_{221}$ : Degree_Uniqueness $=\frac{\text { Uniqueness }_{t}}{\text { Uniqueness }(t-1)}$ \\
\hline
\end{tabular}

Table 4. Numerical Example: Data

\begin{tabular}{|c|c|c|c|c|}
\hline \multirow{2}{*}{$\begin{array}{l}\text { Strategies } \\
\left.\text { (expenseRatio_s } s_{\text {is }}\right)\end{array}$} & \multicolumn{2}{|c|}{ Enterprise $1\left(e_{1}\right) \rightarrow$ Budget $\left(b_{1}\right)=100$} & \multicolumn{2}{|c|}{ Enterprise $2\left(e_{2}\right) \rightarrow$ Budget $\left(b_{2}\right)=150$} \\
\hline & $\mathbf{k p i}_{111}\left(\right.$ priority_kpi $\left.\mathbf{1}_{111}=0,3\right)$ & $\mathbf{k p i}_{121}\left(\right.$ priority_kpi $\left.\mathbf{i}_{121}=0,7\right)$ & $\mathrm{kpi}_{211}$ (priority_kpi ${ }_{211}=0,6$ ) & $\mathbf{k p i}_{221}$ (priority_ $\mathrm{kpi}_{221}=0,4$ ) \\
\hline$s_{11}{ }^{1}(5$ m.u. $)$ & $\nabla \mathrm{kpi}_{111}^{11}=1$ & $\nabla \mathrm{kpi}_{121}^{11}=0$ & $\nabla \mathrm{kpi}_{211}^{11}=-0,3$ & $\nabla \mathrm{kpi}_{221}^{11}=-1$ \\
\hline$s_{12} 1(6$ m.u. $)$ & $\nabla \mathrm{kpi}_{111}^{12}=0$ & $\nabla \mathrm{kpi}_{121}^{12}=1$ & $\nabla \mathrm{kpi}_{211}^{12}=1$ & $\nabla \mathrm{kpi}_{221}^{12}=0,5$ \\
\hline$S_{21} 1(10$ m.u. $)$ & $\nabla \mathrm{kpi}_{111}^{21}=-0,7$ & $\nabla \mathrm{kpi}_{121}^{21}=1$ & $\nabla \mathrm{kpi}_{211}^{21}=1$ & $\nabla \mathrm{kpi}_{221}^{21}=0,6$ \\
\hline $\mathrm{S}_{22}{ }^{1}(4$ m.u. $)$ & $\nabla \mathrm{kpi}_{111}^{22}=-1$ & $\nabla \mathrm{kpi}_{121}^{22}=0$ & $\nabla \mathrm{kpi}_{211}^{22}=0,6$ & $\nabla \mathrm{kpi}_{221}^{22}=$ \\
\hline
\end{tabular}




\section{SA_and_VA_Example_AnyLogic}

\begin{tabular}{|c|c|c|}
\hline \multicolumn{2}{|l|}{ Optimizati } & \multirow[b]{3}{*}{ Best } \\
\hline \multicolumn{2}{|c|}{ Run optimization } & \\
\hline & Current & \\
\hline Iteration: & $\begin{array}{r}5,0002 \\
\text { infeasible }\end{array}$ & 4,647 \\
\hline Objective: & 25.996 & 44.955 \\
\hline \multicolumn{3}{|l|}{ Parameters } \\
\hline s11 & 16.821 & $1.044 \mathrm{E}-8$ \\
\hline s12 & 12.876 & 16.67 \\
\hline s21 & 4.285 & 15 \\
\hline S22 & 35.439 & $1.919 \mathrm{E}-8$ \\
\hline ExpenseRatio_s11 & 0.2 & 0.2 \\
\hline ExpenseRatio_S12 & 0.167 & 0.167 \\
\hline ExpenseRatio_s21 & 0.1 & 0.1 \\
\hline ExpenseRatio_s22 & 0.25 & 0.25 \\
\hline $\begin{array}{l}\text { Copy the best solution } \\
\text { to the clipboard }\end{array}$ & $>$ & copy \\
\hline
\end{tabular}

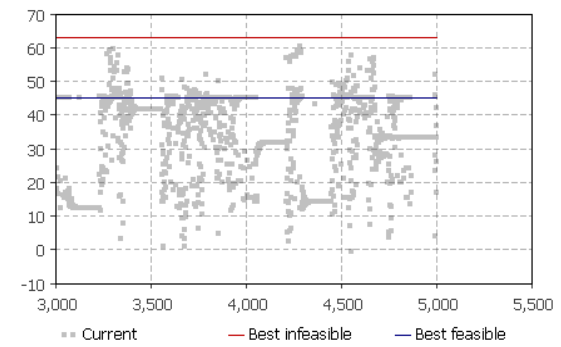

Fig 4. Optimisation Results

The results obtained from the example seem to be logical. However, in a consortium consisting of more entities the solution is not as trivial; being, the developed model, useful to handle higher amounts of data. Nevertheless, gathering these data is seen as a drawback to implement the model. Taking into account that a collaborative network is characterised by uncertainty and incomplete information, the provided model should deeply contemplate these restrictions and consider the possibility of providing a more realistic approach in terms information collection and also deal with the dynamism characterising the network. Despite these limitations, the approach developed implies an original scientific contribution in terms of collaborative strategic planning, partners' selection, and assessing and enhancing the enterprises readiness for collaboration.

\section{Conclusions}

This paper provides an approach, based on dynamic systems, to tackle the possible incoherencies among the activated strategies and the values held in each enterprise, guaranteeing the strategies alignment. This paper is contextualised on the creation of new collaborative consortia to deal with new market opportunities. The novel concept of emergent core value is considered consisting on: (i) new values and (ii) values that temporarily change the priority when a new consortium is formed. The proposed approach deals with the coherence between the strategies and the emergent value system. The approach is applied through defining objectives based on the core values that belong to the emergent value system and setting up the strategies that allow reaching these objectives. With the provided method, the aligned strategies that are to be activated are identified, enabling the coherence between these strategies and the emergent value system. An example is developed showing the solution approach applicability. 
Future research lines are led to apply the proposed solution in a real collaborative network consortium. Furthermore, an improved approach could be reached through considering a new variable to compute the degree of coherence between the activated strategies and the value systems; in order to have a more accurate solution approach. As the adopted approach focuses on collaborative consortia with a limited length, future work could extend the approach to long term associations; in order to define how the strategies activated in a determined periods of time affect the values held by the enterprises in the long term context.

Acknowledgments. This work was funded in part by the European Commission through the GloNet project (FP7 programme) and the Programa Val $i+d$ para investigadores en formación (ACIF). The authors also thank the contributions from their partners in this project.

\section{References}

1. Camarinha-Matos, L.M., H. Afsarmanesh, M. Ollus. Ecolead and CNO Base Concepts, in Methods and Tools for Collaborative Networked Organizations. 2008. Springer US. p. 332.

2. Poler, R., L.M. Carneiro, T. Jasinski, M. Zolghadri, P. Pedrazzoli. Intelligent Nonhierarchical Manufacturing Networks. Networks and Telecomunications Series. 2012. iSTE WILEY. 448.

3. Bititci, U., T. Turner, D. Mackay, D. Kearney, J. Parung, D. Walters. Managing synergy in collaborative enterprises. Production Planning \& Control. 2007. 18(6): p. 454-465.

4. Macedo, P., A. Abreu, and L.M. Camarinha-Matos. A method to analyse the alignment of core values in collaborative networked organisations. Production Planning \& Control, 2010. 21(2): p. 145-159.

5. Andres, B., R. Poler, Computing the Strategies Alignment in Collaborative Networks, in Enterprise Interoperability VI. 2014, Springer International Publishing. p. 29-40.

6. Macedo, P., Models and tools for value systems analysis in collaborative environments, in $\mathrm{PhD}$ Thesis, New University of Lisbon. 2011.

7. Macedo, P. and L.M. Camarinha-Matos. A qualitative approach to assess the alignment of Value Systems in collaborative enterprises networks. Computers \& Industrial Engineering, 2013. 64(1): p. 412-424.

8. Findlay-Brooks, R., W. Visser, T. Wright.Cross-Sector Partnership as an Approach to Inclusive Development. University Cambridge Programme for Industry Research Paper Series.2007. Volume, 4

9. Greenwood, R. and C.R. Hinings, Organizational design types, tracks and the dynamics of strategic change. Organization studies, 1988. 9(3): p. 293-316.

10. Gray, B. The process of partnership construction: Anticipating obstacles and enhancing the likelihood of successful partnerships for sustainable development. Partnerships, Governance and Sustainable Development. Reflections on Theory and Practice, 2007. p. 27-41.

11. Camarinha-Matos, L.M. and H. Afsarmanesh, Elements of a base VE infrastructure. J. Computers in Industry, 2003. 51(2): p. 139-163.

12. Kasanen, E., K. Lukka, and A. Siitonen, The Constructive Approach in Management Accounting Research. Journal of Management Accounting Research, 1993. Vol 5. p. 21.

13. AnyLogic. 2014 [cited; Available from: http://www.anylogic.com/ 